\title{
CHEMICAL SEQUENCING OF DISULFIDE-CROSSLINKED OLIGODEOXYRIBONUCLEOTIDES
}

\author{
Patrick C. Swanson and Gary D. Glick* \\ Department of Chemistry, University of Michigan \\ 930 North University Avenue, Ann Arbor, Michigan 48109-1055
}

(Received in USA 26 July 1993; accepted 17 August 1993)

\begin{abstract}
Oligodeoxyribonucleotides containing a novel disulfide crosslink are shown to be amenable to chemical sequencing using standard sequencing reagents following reduction of the disulfide with DTT and selective alkylation of the free thiols with $N$-ethylmaleimide. This strategy will facilitate conformational and molecular recognition studies of DNA stabilized by crosslinking.
\end{abstract}

The number of methods to crosslink DNA has increased dramatically over the last several years. ${ }^{1}$ While such procedures are useful tools to study nucleic acid structure and function, the presence of the crosslink itself poses difficulties in the application of techniques normally used to characterize DNA. For example, experiments designed to probe DNA conformation or DNA recognition elements usually require the generation of reference sequencing ladders using base-specific modifying reagents. However, obtaining a complete, uninterrupted sequence from crosslinked DNA using chemical methods has not been achieved. This is due both to incompatibilities between the crosslink and sequencing reagents, and the irreversibility of the crosslinking reaction, which results in aberrant migration behavior of cleaved and modified DNA on sequencing gels. In addition, cnzymatic sequencing only provides information up to the point of modification, where the polymerase reaction is terminated, $1 \mathrm{e}$ and is not applicable for sequencing small oligonucleotides. We report that disulfide crosslinked $\mathrm{DNA}^{2}$ is amenable to chemical sequencing following reduction of the disulfide and selective alkylation of the resulting thiols. This strategy yields unambiguous sequencing ladders suitable for structural or molecular recognition studies of crosslinked DNA.

Prior to sequencing, [ $\left.{ }^{32} \mathrm{P}\right] 5^{\prime}$ end-labeled 2 (Figure 1) ${ }^{2 \mathrm{~b}}$ was reduced with dithiothreitol $(65 \mathrm{mM}$ in $0.1 \mathrm{~N}$ $\mathrm{Na}_{2} \mathrm{PO}_{4}, \mathrm{pH} 8$ ) for $8 \mathrm{~h}$ at $4{ }^{\circ} \mathrm{C}$ followed by ethanol precipitation and selective alkylation with $N$-ethylmaleimide (NEM, $5 \mathrm{mM}$ in $50 \mu \mathrm{L}$ of $50 \mathrm{mM}$ Tris-Cl, $\mathrm{pH} 8.4$ at $37^{\circ} \mathrm{C}$, with $5 \mu \mathrm{L}$ aliquots of $50 \mathrm{mM}$ NEM added at $0.5 \mathrm{~h}$ intervals) ${ }^{3}$ After ethanol precipitation, the DNA was resuspended in formamide and fractionated on a denaturing $20 \%$ polyacrylamide gel. The linear DNA 3 was excised, electroeluted, desalted using a NAP-5 column (Pharmacia) and used in sequencing reactions without further modifications to the sequencing protocol. $^{4}$ Figure 2 shows 1 and 3 subjected to standard sequencing reactions. Except for the slight difference in gel mobility, the cleavage pattern of 3 resembles the cleavage pattern of 1 by gel electrophoresis indicating that NEM is selective for thiols and that the adduct is stable toward standard sequencing reagents. Alkylation of the free thiols was required to avoid rapid reoxidation

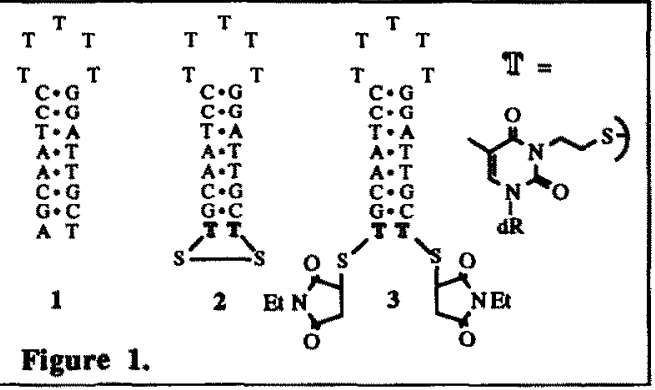


to the disulfide during the course of the sequencing protocol.

In conclusion, these results show that DNA containing an engineered disulfide crosslink may be chemically sequenced following reduction and selective alkylation of the thiols. Indeed, we have successfully applied this technique in conformational studies of duplex and triplex DNA containing disulfide crosslinks. 5 This finding should make disulfide-modified DNA fully accessible to the variety of experiments normally used to study nucleic acid structure and function. Finally, the reduction-alkylation strategy may he generally useful in studies of DNA containing other thiol modifications. ${ }^{1 \mathrm{~d}, 6}$

Figure 2. Sequencing reactions for $C, G$, $G+A$ and $T$ residues were performed using hydroxylamine hydrochloride $\mathrm{pH} 6$, dimethyl sulfate, formic acid and potassium permanganate, respectively. 4 Modified DNA was cleaved by heating in $10 \%$ piperidine at $90^{\circ} \mathrm{C}$ for $30 \mathrm{~min}$. Cleavage products were resolved on a $20 \%$ polyacrylamide sequencing gel. Lanes 1-3; uncut 1,2 , and 3 , respectively. Lanes 4-5; piperidine cleavage of unmodified 1 and 3 showing the selectivity of alkylation. Lanes 6-13; sequencing reactions of 1 and 3. A minor band migrating as 2 in sequencing reactions of 3 is due to loss of the thiol protecting group and reoxidation to 2 during piperidine cleavage.

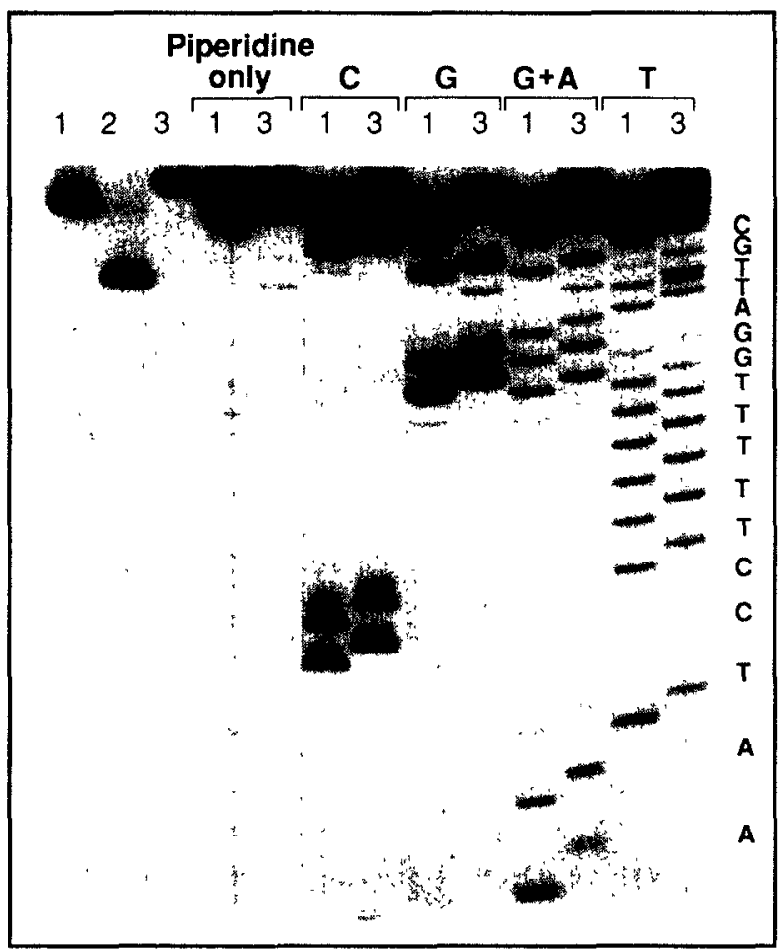

Acknowledgment: Supported by a grant from the NIH (GM 46831). G.D.G. is the recipient of a National Science Foundation Young Investigator Award and an American Cancer Society Junior Faculty Research Award. P.C.S. is the recipient of an NIH Molecular Biophysics Predoctoral Fellowship (T32 GM 08270).

\section{References:}

1. For representative examples see: (a) Teng, S.P.; Woodson, S.A.; Crothers, D.M. Biochemistry 1989, 28, 3901. (b) Cowart, M.; Benkovic, S.J. Biochemistry 1991, 30, 788. (c) Blatter, E.E.; Ebright, Y.W.; Ebright, R.H. Nature (London) 1993, 359, 650. (d) Ferentz, A.E; Verdine, G.L. J. Am. Chem. Soc. 1991, 113, 4000. (e) Cullinane, C; Wickham, G.; McFadyen, W.D.; Denny, W.A.; Palmer, B.D.; Phillips, D.R. Nucleic Acids Res. 1993, 21, 393.

2. (a) Goodwin, J.T.; Glick, G.D. Tetrehedron Lett., in press. (b) Stevens, S.Y., Swanson, P.C., Voss, E. W. Jr.; Glick, G.D. J. Am. Chem Soc. 1993, 115, 1578. (c) Glick, G.D., Osborne, S.E., Knit, D.S.; Marino. J.P. Jr., J. Am Chem. Soc. 1992, 114,5447 . (d) Glick G.D. J. Org. Chem 1991, 56, 6746.

3. Carbon, J.; David, H. Biochemistry 1968, 7, 3851.

4. (a) Maxam, A.M.; Gilbert, W. Methods Enzymol. 1980, 65, 499. (b) Rubin, C.M.; Schmid, C.W. Nucleic Acids Res. 1980, 8, 4613. (c) McCarthy, J.G. Nucleic Acids Res. 1989, $17,7541$.

5. Goodwin, J.T.; Osbome, S.O.; Swanson, P.C.; Glick, G.D. manuscript in preparation.

6. (a) Zukerman, R.; Corey, D.; Shultz, P. Nucleic Acids Res. 1987, 15, 5305. (b) Chu, B.C.F.; Orgel, L.E Nucleic Acids Res. 1988, 16, 3671. (c) Bradley, D.H.; Hanna, M.M. Tetrahedron Lett. 1992, 33, 6223. 